\title{
Influences on Adolescent Help-Seeking for Mental Health Problems
}

\begin{tabular}{|r|l|}
\hline Journal: & Journal of Psychologists and Counsellors in Schools \\
\hline Manuscript ID & JGC-OA-2020-0022.R2 \\
\hline Keywords: & help-seeking, school counsellor, mental health, adolescents, barriers \\
\hline Abstract: & $\begin{array}{l}\text { Seeking help for mental health concerns is critical for improving } \\
\text { wellbeing and preventing the development of mental health disorders, } \\
\text { yet many adolescents with mental health problems fail to seek } \\
\text { professional help. It is well established that young people with mental } \\
\text { health problems face a variety of barriers to help-seeking; however, little } \\
\text { is known about the way in which these barriers interact to impact upon } \\
\text { the help-seeking process. Guided by the Reasoned Action Approach } \\
\text { relationship between factors that influence help-seeking. Results } \\
\text { revealed that mental health knowledge significantly predicted help- } \\
\text { seeking intentions, whilst attitudes did not. Gender differences were } \\
\text { identified for help source preferences. The current study contributes to } \\
\text { knowledge on the relationship between key variables that influence the } \\
\text { adolescent help-seeking process. Findings highlight the importance of } \\
\text { mental health knowledge in predicting help-seeking intentions and } \\
\text { provide support for interventions that focus on improving mental health } \\
\text { literacy in adolescents. }\end{array}$ \\
\hline
\end{tabular}

\section{SCHOLARONE Manuscripts}


RUNNING HEAD: ADOLESCENT HELP-SEEKING

Title: Influences on Adolescent Help-Seeking for Mental Health Problems

Running Head: Adolescent Help-Seeking

Word Count: 4930

Abstract: Seeking help for mental health concerns is critical for improving wellbeing and preventing the development of mental health disorders, yet many adolescents with mental health problems fail to seek professional help. It is well established that young people with mental health problems face a variety of barriers to help-seeking; however, little is known about the way in which these barriers interact to impact upon the helpseeking process. Guided by the Reasoned Action Approach (Fishbein \& Ajzen, 2010), this study investigated the predictive relationship between factors that influence helpseeking. Results revealed that mental health knowledge significantly predicted helpseeking intentions, whilst attitudes did not. Gender differences were identified for help source preferences. The current study contributes to knowledge on the relationship between key variables that influence the adolescent help-seeking process. Findings highlight the importance of mental health knowledge in predicting help-seeking 
ADOLESCENT HELP-SEEKING

intentions and provide support for interventions that focus on improving mental health

literacy in adolescents.

Keywords: help-seeking, school counsellor, mental health, adolescents, barriers 
ADOLESCENT HELP-SEEKING

\section{Introduction}

Rates of mental health problems amongst Australian adolescents have increased at an alarming rate over the past decade (Australian Bureau of Statistics, 2018a, 2018b). Mental health problems negatively affect how a person thinks, feels and behaves and may or may not be part of a diagnosed mental health disorder (Sawyer et al., 2001). Mental health problems can have profound impacts on wellbeing and functioning, yet young people with mental health problems often delay or avoid seeking professional help (Lawrence et al., 2015; McGorry \& Purcell, 2009; Mission Australia, 2017).

Seeking help for mental health problems is critical for preventing the development and progression of mental health disorders (McGorry \& Mei, 2018). Although definitions vary, help-seeking can be thought of as "an adaptive coping process that is the attempt to obtain external assistance to deal with a mental health concern" (Rickwood \& Thomas, 2012, p. 180). External assistance or 'help' for mental health concerns can be sought from 'formal' sources (e.g. psychologists and doctors) and 'informal' sources (i.e. teachers, family and friends). 


\section{ADOLESCENT HELP-SEEKING}

Help-seeking for mental health problems during adolescence, when a majority of

associated disorders emerge, has the capacity to generate better outcomes than

intervention at any other time in the lifespan (Access Economics, 2009; Catania,

Hetrick, Purcell, \& Newman, 2011; Littlefield, 2008; ReachOut Australia \& Mission

Australia, 2018). Early intervention is the key to achieving successful mental health

outcomes, reducing suicide rates and reducing the burden of mental disorders (Access

Economics, 2009; Catania et al., 2011; Littlefield, 2008; ReachOut Australia \& Mission

Australia, 2018).

Unfortunately, around one in three (34.9\%) adolescents with mental health

problems fail to seek professional help (Lawrence et al., 2015). Research has

consistently found that male and female adolescents show a strong preference for

informal sources of help like friends and parents over formal sources like psychologists

and doctors, irrespective of their age, gender and residential location (Mission Australia,

2018; Rickwood et al., 2005). However, females consistently report greater intentions to

seek help from informal sources like friends and teachers, and familiar formal sources

like school psychologists than their male counterparts, whilst males report greater

intentions to seek help from mental health community agencies and general 
ADOLESCENT HELP-SEEKING

practitioners (Australian Institute of Family Studies, 2017; Mission Australia, 2017;

Ratnayake \& Hyde, 2019). Whilst male and females report similar levels of actua/helpseeking behaviour in early adolescence, studies have indicated that males become less likely to actually seek help than their female counterparts as they increase in age (Lawrence et al., 2015; Rickwood et al., 2005).

\section{Barriers to Help-Seeking}

Research indicates that there a range of attitudinal and practical barriers that prevent adolescents from seeking professional help and contribute to gender differences in help-seeking behaviour. Poor mental health literacy has been identified within the literature as a key barrier to help-seeking in this population (Gulliver, Griffiths, \& Christensen, 2010) where help-seeking is the outcome of improved mental health knowledge. Mental health literacy (MHL) was first defined by Jorm (1997) as knowledge and beliefs about mental disorders, which aid their recognition, management or prevention. This definition has since been updated to encompasses six attributes where help-seeking is specifically outlined as a factor; these attributes include the ability to recognise mental health disorders, identify risk factors, know how to seek and obtain mental health information, knowledge of prevention, identify the best treatments and resources available as well as how to 


\section{ADOLESCENT HELP-SEEKING}

access this support (Jorm, 2015). Recent research has identified the importance of advancing developmentally appropriate frameworks of mental health literacy in children and young people as traditional definitions are developed from research with adult populations (Bale, Grové, \& Costello, 2018; Riebschleger, Grove, Cavanaugh \& Costello, 2017). Such research has advanced the conceptualisation and understanding of specific mental health needs of youth, their wellbeing and help seeking behaviours. Recent research by Bale et al. (2020) has proposed a new framework for mental health literacy in children. The model identifies six themes that encompass recognising changes in mental health, help-seeking actions, supports available, mental health influences, coping and resilience, and attitudes (Bale, Grove, Costello, 2020), researchers highlight that the actioning of help-seeking by young people is impacted by knowledge of how to access support.

Research indicates that adolescents often do not have adequate knowledge about what health services are available and how to access them (Jorm et al., 1997; Rickwood \& Thomas, 2012). They can also have difficulty appraising their distress levels as normal or abnormal. Perceived and self-stigma and embarrassment consistently emerge in the literature as prominent barriers to help-seeking for mental health problems (Gulliver et al., 2010; Rickwood et al., 2005). Associating help-seeking for mental health concerns with being a sign of personal weakness is well established in the literature, particularly amongst men and individuals residing in regional areas 
ADOLESCENT HELP-SEEKING

(Kõlves et al., 2012; Reavley \& Jorm, 2012). A lack of accessibility to mental health

services is another prominent barrier to help-seeking by adolescents (Gulliver et al.,

2010). Even if a young person fully intends to seek help, services must be available,

affordable and accessible by transport and a person must have time to access it, if help

is to actually be sought. To improve help-seeking intentions and actual behaviour, it's

important that the way in which such barriers interact is well understood.

\section{Models of Help-Seeking}

Applying existing theories of help-seeking to adolescent help-seeking behaviour can provide greater insight into how these factors interact to influence the help-seeking process. Help-seeking literature has relied heavily on several major theories of behaviour to explain the help-seeking process, these are summarised in Table 1.

$$
\text { [Insert Table } 1 \text { here] }
$$

A criticism of guiding models and frameworks of help-seeking is that they do not adequately incorporate several key determinants of help-seeking behaviour or reflect the dynamic nature of the help-seeking process, and therefore much of the process 


\section{ADOLESCENT HELP-SEEKING}

remains unexplained (Murray, 2005). In some model's important factors impacting the

help-seeking process (such as practical access to services and mental health literacy)

are ignored or considered as external influences on the model (Ajzen \& Fishbein, 1980;

Fishbein \& Ajzen, 1975; Rickwood et al., 2005). One model that could potentially

address these limitations is the Reasoned Action Approach (RAA; see Figure 1;

Fishbein \& Ajzen, 2010).

[Insert Figure 1 here]

The RAA is the latest of Fishbein and Ajzen's behaviour models (Ajzen, 1985;

Fishbein \& Ajzen, 1975). As represented in Figure 1, it proposes that attitudes influence intentions by mediating the relationship between background factors (like knowledge) and intentions. Additionally, unlike any of the previously applied frameworks, the RAA allows for consideration of the way in which actual control influences the translation of help-seeking intentions to behaviour (Fishbein \& Ajzen, 2010).

\section{The Current Study}




\section{ADOLESCENT HELP-SEEKING}

Investigating the relationship between mental health knowledge and help-seeking

attitudes (the two key components of mental health literacy), service accessibility, helpseeking intentions and help-seeking behaviours will contribute to current understanding of how barriers influence the help-seeking process and guide interventions to improve help-seeking behaviour.

[Insert Figure 2 here]

Guided by the RAA, the present study aimed to examine possible differences in helpseeking determinants, help-seeking intentions and behaviours reported by male and female adolescent students. It was predicted that female students would report greater mental health literacy (knowledge and attitudes) towards mental health problems than male students. It was also hypothesised that there would be no gender difference between overall help-seeking intentions and behaviours, but female students would prefer to seek help from informal sources than their male counterparts. The current study also examined the relationship between mental health knowledge and attitudes, service accessibility, help-seeking intentions and actual help-seeking behaviour. It was hypothesised that mental health attitudes would mediate the predictive relationship between knowledge and help-seeking intentions. It was also predicted that help source 
ADOLESCENT HELP-SEEKING

accessibility would moderate the relationship between help-seeking intentions and

actual help-seeking behaviours amongst students with an identified mental health

concern.

\section{Method}

\section{Participants}

Participating schools were recruited via mail invitation and convenience

sampling. Three schools were recruited included a government co-educational school in Inner Melbourne (high SES location), an independent girls' school in Inner Sydney and an independent co-educational school in regional New South Wales (both independent schools were fee-paying). All schools deliver universal wellbeing programs and employ wellbeing support staff e.g. psychologists, counsellors and/or wellbeing coordinators. In total, 172 Grade 10, 11 and 12 participants took part in the study. The sample consisted of 111 females and 61 males, ranging in age from 15 to 17.5 years $(M=16.02, S E=.05)$. $95.3 \%$ of participants were located in urban areas, $81.4 \%$ of participants reported being born in Australia, whilst $8.1 \%, 5.8 \%$ and $4.7 \%$ of participants identified being born in Asia, Europe or other continents, respectively. $1.7 \%$ of participants identified as 


\section{ADOLESCENT HELP-SEEKING}

Aboriginal or Torres Strait Islander, and 3.5\% of participants identified as international students.

\section{Procedure}

Ethical approval for this study was obtained from the University Human Research Ethics Committee and permission to conduct the study was attained from the relevant state department of education and school principals. Parents/guardians and students were provided with a Plain Language Statement (PLS) which described the nature and purpose of the research, and signed consent was obtained from both students and parents/guardians. Student assent was also required before students progressed through the online survey. All participants required access to a computer, tablet or smartphone to complete the survey hosted by Qualtrics. The survey included four questionnaires and lasted approximately 15-20 minutes. A prompted response procedure was used to minimise the potential for skipped questions, and participants were required to complete and submit the survey in one sitting.

\section{Materials}

Participants were required to complete an online survey battery hosted by

Qualtrics. The survey lasted approximately 15-20 minutes and included four questionnaires which measured mental health literacy (MHL), help service accessibility, help-seeking intentions and help-seeking behaviours. 


\section{ADOLESCENT HELP-SEEKING}

MHL was assessed using the 35-item Mental Health Literacy Scale (MHLS;

O’Connor \& Casey, 2015). Participants were asked to indicate on a 5-point Likert scale the extent to which they agreed or disagreed with 15 statements relating to mental health knowledge and 20 statements relating to mental health attitudes. The MHLS, overall, has acceptable test-retest reliability $r(69)=.797, p<.001$, and good internal reliability, with a reported Cronbach's alpha of .87 (O'Connor \& Casey, 2015). For the current sample, the attitudes and knowledge subscales demonstrated good and questionable degrees of internal consistency, with Cronbach's alphas of .87 and .65, respectively. It has been argued that instruments that have a questionable alpha can still prove useful if they assess a broad range of knowledge (Berger and Hänze, 2015; Schmitt, 1996).

Service Accessibility Questionnaire (SAQ)

Help service accessibility was assessed using the Service Accessibility Questionnaire (SAQ) which was developed specifically for this study, guided by questions included in ReachOut and Mission Australia's Youth Survey (2018). Participants were asked to indicate on a 5-point Likert scale the extent to which they agreed or disagreed with three statements relating to service affordability, transport and 


\section{ADOLESCENT HELP-SEEKING}

timing (I could not afford to get professional help even if I wanted to; I don't have transport to

get to a service; Even if I wanted to, I wouldn't have time to get professional help). Participants

were also asked to select mental health services (e.g. school psychologist, family doctor

etc.) available to them. For the current sample, the SAQ demonstrated acceptable

internal consistency with a Cronbach's alpha of .71.

General Help Seeking Questionnaire (GHSQ)

Intentions to seek help were assessed using the General Help-Seeking

Questionnaire (GHSQ; Wilson, Deane, Ciarrochi, \& Rickwood, 2005). Participants were asked to indicate on a 7-point Likert scale the likelihood they'd seek help for personal or emotional problems and suicidal ideation from sources listed. The GHSQ has excellent test-retest reliability ( $r=.92$; Wilson et al., 2005) and good internal consistency with a Cronbach's alpha of .85. For the current sample, the GHSQ demonstrated acceptable internal consistency with a Cronbach's alpha of .79.

Actual Help-Seeking Questionnaire (AHSQ)

Help-seeking behaviour was assessed using the Actual Help-Seeking Questionnaire (AHSQ; Rickwood \& Braithwaite, 1994). Participants were asked to identify whether they had or had not sought help for personal or emotional problems 
ADOLESCENT HELP-SEEKING

from a list of informal sources (e.g. parent, friend, teacher) and formal sources (e.g.

mental health professional, doctor or phone help line) by providing a "yes" (1) or "no" (0)

response, and then describing the problem. Only participants that described having

experienced personal or emotional problems over the past 4 weeks received a score for formal help-seeking and informal help-seeking on the AHSQ.

\section{Data Analysis}

All analyses were carried out using SPSS Version 25. Prior to analysis, data were examined for violations of normality and homogeneity of variances. Chi-square tests of association revealed no significant differences between group characteristics on any of the relevant analyses. One-way ANOVAs were conducted to investigate the effects of gender on knowledge, attitudes, service accessibility and help-seeking intentions within the full sample and formal and informal help-seeking behaviour amongst those that reported a recent mental health concern. Independent sample t-tests were used to investigate the gender differences in help-seeking intentions from specific help sources. Process regression analysis was used to investigate the way in which factors related to one another (Hayes, 2013) 
ADOLESCENT HELP-SEEKING

\section{Results}

There were no significant main effects of gender on any of the outcome variables, $p s$ >

.08. (See Table 2 for mean scores and associated standard errors).

$$
\text { [Insert Table } 2 \text { here] }
$$

Gender differences were identified for source and problem type in regard to helpseeking intentions. The results revealed that females $(M=5.61, S E=.14)$ were more likely to indicate they would seek help from friends for personal and emotional problems than their male counterparts $(M=5.08, S E=.22), t(170)=2.13, p=.04, d=.34$.

Similarly, females $(M=5.64, S E=1.35)$ were more likely to report that they would seek help from a mental health professional for personal and emotional problems than males $(M=5.11, S E=.22), t(170)=2.14, p=.03, d=.34$. Males indicated significantly greater intentions to seek help for suicidal ideation from a general practitioner $(M=5.05, S E=$ $.25)$ than their female counterparts $(M=4.23, S E=.20), t(170)=2.53, p=.01, d=.43$. In total, $18.6 \%$ of students in the total sample reported seeking help for a mental health concern. Of these students, $87.1 \%$ and $19.4 \%$ sought help from at least one informal or formal source of help, respectively. See Table 3 for a breakdown of help- 
ADOLESCENT HELP-SEEKING

seeking behaviour amongst students that identified experiencing a recent mental health

concern.

[Insert Table 3 here]

Pearson correlation coefficients revealed a statistically significant, moderate

correlation between knowledge and attitudes and knowledge and accessibility within the

full sample, ps <.01 (see Table 5). There was also a significant weak correlation

between knowledge and help-seeking intentions and attitudes and accessibility, $p s<$

.05 .

Table 4.

[Insert Table 4 here]

As shown in Figure 3, path regression analysis revealed that knowledge was a significant, direct predictor of both attitudes, $b=.77, t(1,170)=6.21, p<.001(a)$, and help-seeking intentions, $b=.65, t(1,170)=2.06, p=.04(c)$. However, attitudes did not significantly predict help-seeking intentions, $p=.95$, and did not mediate the relationship between knowledge and intentions. Together, the direct effect of knowledge and indirect 
ADOLESCENT HELP-SEEKING

effect of knowledge via attitudes, did not significantly predict intentions, $F(2,169)=2.55$,

$p=.08, R^{2}=.03$

[Insert Figure 3 here]

Regression analysis indicated that within the subgroup of students that reported

experiencing a recent mental health concern, neither help-seeking intentions or

accessibility significantly predicted levels of formal help-seeking and accessibility did not

moderate the relationship between intentions and formal help-seeking $p s>.15$. The

results also indicated that accessibility did not moderate the relationship between help-

seeking intentions and actual formal or total help-seeking behaviour, ps > 09 .

\section{Discussion}

The present study aimed to examine gender differences in the mental health

knowledge and attitudes, help-seeking intentions and help-seeking behaviours of

adolescents. The study revealed no significant differences between the mental health

knowledge and attitudes, overall help-seeking intentions or formal help-seeking

behaviours for male and female students. Recent broad-scale studies have found the 


\section{ADOLESCENT HELP-SEEKING}

level of help-seeking intentions and preference for informal sources of help to be similar for young males and females in their early teenage years (Australian Institute of Family Studies, 2017; Mission Australia, 2017). This trend is reflected in the current study.

In relation to specific type of help source, females in the present study reported being significantly more likely to seek help from their friends than males, which is consistent with recent findings within the help-seeking literature (Australian Institute of Family Studies, 2017; Mission Australia, 2017). Interestingly, in the current study, male students reported greater intentions to seek help from a doctor for suicidal ideation than female students. This is consistent with findings from a recent study which examined help-seeking intentions in Australian high school students (Ratnayake \& Hyde, 2019). The authors found that male students were more likely to report intentions to seek help from a doctor or general practitioner for personal and emotional problems and suicidal ideation than female students. These findings indicate a male preference for dealing with mental health issues in a more private or medical manner, e.g. through consultation with a medical practitioner, which is consistent with the Mission Australia (2017) report where males indicated a preference to seek help from community agencies. 


\section{ADOLESCENT HELP-SEEKING}

Interestingly, only around one fifth of students that identified having sought some

sort of help for a recent mental health concern reported seeking that help from a formal

source. Such a pattern is consistent with research that shows adolescents have a

strong preference for informal sources of help (such as parents or friends) irrespective

of their age and gender (Mission Australia, 2018; Rickwood et al., 2005). The level of

formal help-seeking within this population is relatively low in comparison to recent

figures from the Australian Child and Adolescent Survey of Mental Health and Wellbeing

(Lawrence et al., 2015). This survey found that $65.1 \%$ of Australians aged $12-17$ with

mental disorders sought formal help in the previous 12 months. As the current study did

not measure students' actual mental health status, it is not possible to ascertain whether

students' mental health problems were diagnosable conditions that may necessitate

professional help. It could also be reasoned that high levels of informal help-seeking

and school-based resources such as wellbeing programs and structures in place in the

participating schools may have reduced the need for formal help-seeking within this

population. In other words, students had access to internal support resources as a

result of wellbeing programs within the school thereby potentially reducing the need for

formal help-seeking. 


\section{ADOLESCENT HELP-SEEKING}

The second aim of this study was to examine the relationship between mental

health knowledge and attitudes, service accessibility, help-seeking intentions and helpseeking behaviour. In the current study, knowledge was a significant predictor of variance in overall help-seeking intentions. This provides partial support for the Reasoned Action Approach (RAA; Fishbein \& Ajzen, 2010). The RAA extends upon the Theories of Planned Behaviour and Reasoned Action by adding background factors (like knowledge) as determinants of intentions to perform a behavior like help-seeking (Ajzen, 1985; Fishbein \& Ajzen, 1975; Fishbein \& Ajzen, 2010). The current results provide further support for the importance of mental health knowledge (a key construct within mental health literacy) in improving help-seeking intentions (Hart et al., 2018; Lubman et al., 2016). Whilst the findings indicate that knowledge is indeed important in predicting help-seeking intentions, in the current study only a small portion of the variance in help-seeking intentions was predicted by knowledge and attitudes. This reflects the complexity of the help-seeking process and highlights the importance of considering a variety of factors when designing future research and developing interventions (Damghanian \& Alijanzadeh, 2018; Fishbein \& Ajzen, 2011). 


\section{ADOLESCENT HELP-SEEKING}

Interestingly, in the current study, attitudes did not significantly predict help-

seeking intentions, nor mediate the relationship between knowledge and intentions as

was hypothesised. This is inconsistent with the RAA and behaviour models before it,

and past research which has linked negative help-seeking attitudes with low help-

seeking intentions (Andrews, Issakidis, \& Carter, 2001). However, the current study's

results are consistent with prior research amongst Australian university students with

moderate to severe symptoms of distress and the results of a study of 778 adolescents

located in rural New South Wales. Both studies found that negative attitudes towards

help-seeking did not significantly account for variation in help-seeking intentions

(Rughani et al., 2011; Vogel \& Wester, 2003). However, in the adolescent sample, the perceived benefits of help-seeking were significantly associated with help-seeking intentions, which is consistent with research conducted in young adult populations (Rughani et al., 2011; Vogel, Wester, Wei, \& Boysen, 2005). This suggests that attitudes towards the usefulness of professional help may play a more important role than attitudes towards mental health problems in predicting intentions (Rughani et al., 2011). Future research should investigate the role played by specific types of attitudes held by adolescents in predicting help-seeking intentions. 


\section{ADOLESCENT HELP-SEEKING}

In the current study, intention to seek help did not predict formal help-seeking

behaviour amongst those students that identified having experienced a recent mental health concern. Whilst there is limited research on actual help-seeking behaviour within adolescent populations, such results are in contrast to past research with adults which has consistently indicated that intentions are a significant predictor of actual helpseeking behaviour (Armitage \& Conner, 2001; Bitman-Heinrichs, 2017). Additionally, service accessibility did not predict actual formal help-seeking or influence the relationship between intentions and actual behaviour as hypothesised. It is likely that service accessibility assessed in this study better represents perceived accessibility rather than actual accessibility. This may have been confounded further by the inclusion of a non-clinical population.

Overall, these findings contribute to current knowledge on the relationship between key variables that influence the adolescent help-seeking process. In particular, it provides further support for the important role of mental health knowledge in predicting the help-seeking intentions of adolescent students (Hart et al., 2018; Lubman et al., 2016). It also provides support for the most recent version of Fishbein and Azjen's health behaviour models: The Reasoned Action Approach (2010), which built upon 
ADOLESCENT HELP-SEEKING

previous models by proposing that intentions are predicted by background factors such

as knowledge (via attitudes). This has implications for psychology practitioners and

schools in developing targeted interventions towards improving mental health literacy

specifically knowledge, with the aim of improving help-seeking intentions and hopefully

behaviours.

Mental health attitudes did not predict help-seeking intentions or mediate the relationship between knowledge and intentions in the current study which suggests that the relationship between attitudes and help-seeking is complex and may depend on the type of attitude being measured (Rughani et al., 2011; Vogel \& Wester, 2003).

\section{Limitations}

The current findings must be considered within the context of the study limitations. First, whilst 172 students participated in the study, only 31 students were eligible to be included in regression analyses examining the relationship between helpseeking intentions and behaviours, which resulted in minimal power to detect an effect.

Second, as the current study did not measure participants' current mental health state, it was not possible to ascertain whether students' mental health problems were severe enough to require formal help-seeking. Third, as the current study used a non-clinical 


\section{ADOLESCENT HELP-SEEKING}

sample, participants may not have had a solid understanding of true service availability.

Thus, in this sample service accessibility may have been a measure of perceived

service accessibility rather than actual accessibility of services. Actual service

accessibility may have a greater impact on the translation of help-seeking intentions to

behaviours in a population that requires more targeted intervention from a mental health

professional. Assessing actual service availability using more objective measures like

financial means and student-psychologist ratios when examining the translation of

intentions to behaviours in non-clinical populations would be worthwhile. Further, it is

important to note that participants were predominantly recruited from well-resourced

schools that were either fee-paying or located in higher socioeconomic areas, therefore

the sample is not considered representative of the general adolescent population.

\section{Conclusion}

Seeking help for mental health concerns is critical for improving wellbeing and preventing the development of mental health disorders. However, many adolescents with mental health problems fail to seek professional help, preferring to seek help from informal sources like friends and family due to a variety of barriers such as poor mental health literacy. This has implications for schools and highlights the importance of 
ADOLESCENT HELP-SEEKING

upskilling informal help sources like friends and parents to respond to adolescents with

concerns and of educating gatekeepers like teachers on mental health and disorders to

support adolescent referral and engagement with formal help sources when needed

(Australian Institute of Family Studies, 2017; Mission Australia, 2017; Rickwood et al., 2007). Given the preference for informal help-seeking schools can also play a role in ensuring students have access to up-to-date mental health resources to support awareness and early identification of concerns.

In the current study, knowledge about mental health issues predicted students' intentions to seek help, providing support for the Reasoned Action Approach (Fishbein \& Ajzen, 2010) to help-seeking behaviour and interventions that focus on teaching mental health literacy to adolescents. This highlights the importance of school wellbeing programs incorporating mental health literacy skills and in particular development of mental health knowledge to promote better help-seeking behaviour of young people. It would be advisable for schools to review their wellbeing policies and practices to ensure that mental health literacy is embedded in wellbeing curriculum given the identified link between knowledge and positive help-seeking behaviour. Future research should focus on validating the current study's findings with larger samples, samples in areas of less 
ADOLESCENT HELP-SEEKING

advantage and with clinical populations and should also examine the interplay between

other elements within the Reasoned Action Approach framework such as other

individual characteristics, perceived behavioural control and actual control. Such

research will guide the development of interventions aimed at encouraging help-seeking

behaviour, improving mental health outcomes and reducing the prevalence of mental

disorders amongst Australian adolescents.

Tables and Figures

Table 1.

Main Theories Relevant to Adolescent Help-Seeking

Theory Description of help-seeking

Mental Health Literacy Inadequate knowledge of symptoms, of the need to (MHL) seek help and where or how to seek professional help prevent the progression of the help-seeking process. Young people with high levels of mental health literacy have higher levels of help-seeking for mental health issues than those with low mental health literacy (Lam, 2014; Riebschleger et al. 2017).

Stages of Help-Seeking For help-seeking behaviour to occur, an individual Models must experience and label symptoms as problematic, 
attribute symptoms to mental health problems, decide to seek help and select a particular source of help (Rickwood et al. 2005)

Service Utilisation

Framework
Health service use is affected by

one's predisposition to seek help from health services when needed, one's need for care, and the structural or enabling factors that facilitate or impede service utilisation (Aday \& Andersen, 1974).
Theory of Reasoned Action (TRA)
Actual behaviour is a rational decision that is predicted by the intention to behave in a particular way, which is in turn determined by attitudes towards a behaviour and subjective norms about performing that behaviour (Fishbein \& Ajzen, 1975).

\section{Theory of Planned}

Behaviour (TPB)
Actual behaviour is a rational decision that is predicted by the intention to behave in a particular way, and that intentions are in turn determined by attitudes, subjective norms and perceived behavioural control which can also directly predict actual behaviour (Ajzen, 1985). 
ADOLESCENT HELP-SEEKING

Table 2.

Means and Standard Errors of Outcome Variables

Mean SE

Mental health knowledge

Mental health attitudes

Service accessibility

General help-seeking intentions

Actual help-seeking (Formal)*

Actual help-seeking (Informal*
62.25

63.00

15.28

89.92

1.90

.26

\section{.43}

.76

.27

1.60

1.22

.45

* Means and standard errors were obtained from subsample of students with reported mental health concern

Table 3.

Percentage of Students With Recent Mental Health Concern That Sought Help From

Formal and Informal Sources

Help type Source Percentage (\%)




\section{ADOLESCENT HELP-SEEKING}

Formal help source Mental health professional (e.g.

19.4

external or school psychologist)

Doctor (e.g. GP, psychiatrist)

0

Phone help line

0

Informal help source

Partner

19.4

Friend

74.2

Parent

45.2

Other family member

16.1

Teacher

12.9

Other

0

Table 4.

Correlations between variables for all participants

\begin{tabular}{lccc} 
& Knowledge & Attitudes & Accessibility Intentions \\
\hline Knowledge & 1.00 & \\
Attitudes & $.43^{* *}$ & 1.00 &
\end{tabular}




$\begin{aligned} & \text { ADOLESCENT HELP-SEEKING } \\ & \text { Accessibility } \\ & \text { Intentions }\end{aligned}$
$.26^{* *}$
${ }^{* *} p<.01$
${ }^{*} p<.05$

Figure 1. Reasoned Action Approach (Fishbein \& Ajzen, 2010, pg 22)

Figure 2. Application of the Reasoned Action Approach (adapted from Fishbein \& Ajzen, 2010) to Help-Seeking for Mental Health Concerns

Figure 3. Path Analysis- Knowledge, Attitudes and Help-Seeking Intentions 
ADOLESCENT HELP-SEEKING

\section{References}

Access Economics. (2009). The economic impact of youth mental illness and the cost

effectiveness of early intervention. Retrieved from

https://www.orygen.org.au/Policy-Advocacy/Policy-Reports/The-Economic-Impact-

of-Youth-Mental-IIIness-and-th/CostYMH_Dec2009.aspx?ext=.

Aday, L. A., \& Andersen, R. (1974). A framework for the study of access to medical care. Health Services Research, 9(3), 208-220.

Aisbett, D. L., Boyd, C. P., Francis, K. J., Newnham, K., \& Newnham, K. (2017).

Understanding barriers to mental health service utilisation for adolescents in rural

Australia. International Electronic Journal of Rural and Remote Health Research,

Education, Practice and Policy, 91, 399-404.

Ajzen, I. (1985). From Intentions to Actions: A Theory of Planned Behavior. In J. Kuhl \&

J. Beckmann (Eds.), Action Contro/ (pp. 11-39). Berlin, Germany: Springer.

Ajzen, I., \& Fishbein, M. (1980). From Intentions to Actions: A Theory of Planned

Behavior. Englewood Cliffs, NY: Prentice Hall.

Andrews, G., Issakidis, C., \& Carter, G. (2001). Shortfall in mental health service utilisation. British Journal of Psychiatry. doi: 10.1192/bjp.179.5.417 
ADOLESCENT HELP-SEEKING

Andrews, Gavin, Sanderson, K., Corry, J., \& Lapsley, H. M. (2000). Using

epidemiological data to model efficiency in reducing the burden of depression. The Journal of Mental Health Policy and Economics, 3, 175-186. doi: 10.1002/mhp.96

Armitage, C. J., \& Conner, M. (2001). Efficacy of the theory of planned behaviour: A meta-analytic review. British Journal of Social Psychology, 40(4). doi: $10.1348 / 014466601164939$

Australian Bureau of Statistics. (2008). National Survey of Mental Health and Wellbeing. Statistics. doi: Catalogue no. 4326.0

Australian Bureau of Statistics. (2018a). Australia's leading causes of death, 2017 (cat no. 3303.0). Retrieved from http://www.abs.gov.au/ausstats/abs@.nsf/Lookup/by Subject/3303.0 2017 Main Features Intentional self-harm, key characteristics 3 Australian Bureau of Statistics. (2018b). National health survey: first results, Australia 2017-18. Canberra. Retrieved from http://www.ausstats.abs.gov.au/ausstats/subscriber.nsf/0/4B3976684C09F43FCA2 58399001CE630/\$File/4364.0.55.001 - national health survey, first results, 201718.pdf

Australian Institute of Family Studies. (2017). The Longitudinal Study of Australian 


\section{ADOLESCENT HELP-SEEKING}

Children Annual statistical report 2016.

Australian National Health and Medical Research Council. (2000). How to use the

evidence: assessment and application of scientific evidence. How to use the

evidence: assessment and application of scientific evidence. Canberra, Australia.

Bale, J., Grove, C., \& Costello, S. (2020). Building a mental health literacy model and verbal scale for children: results of a Delphi study. Children and Youth Services Review, 109, [104667]. https://doi.org/10.1016/j.childyouth.2019.104667

Bale, J., Grové, C., \& Costello, S. (2018). A narrative literature review of child-focused mental health literacy attributes and scales. Mental Health \& Prevention, 12, 26-35. https://doi.org/10.1016/j.mhp.2018.09.003

Bitman-Heinrichs, R. L. (2017). From attitude to intent to action: Predictors of psychological help-seeking behavior among clinically distressed adults. Retrieved from https://lib.dr.iastate.edu/etd

Catania, L. S., Hetrick, S. E., Purcell, R., \& Newman, L. K. (2011). Prevention and early intervention for mental health problems in 0-25 year olds: Are there evidence-based models of care? Advances in Mental Health, 1011), 3-16.

Damghanian, M., \& Alijanzadeh, M. (2018). Theory of Planned Behavior, Self-Stigma, and Perceived Barriers Explains the Behavior of Seeking Mental Health Services for People at Risk of Affective Disorders. Social Health and Behavior, 1(2), 54-61. 


\section{ADOLESCENT HELP-SEEKING}

doi: $10.4103 /$ SHB.SHB

Deane, F. P., Wilson, C. J., \& Ciarrochi, J. (2001). Suicidal ideation and help-negation:

Not just hopelessness or prior help. Journal of Clinical Psychology, 57(7), 901-914.

doi: 10.1002/jclp.1058

Field, A. (2013). Discovering Statistics using IBM SPSS Statistics. Discovering Statistics using IBM SPSS Statistics. London, UK: Sage Publications Ltd.

Fishbein, M, \& Ajzen, I. (1975). Belief, attitude, intention, and behavior: An introduction to theory and research. Reading, MA: Addison-Wesley.

Fishbein, M, \& Ajzen, I. (2010). Predicting and changing behavior: The reasoned action approach. New York, NY: Psychology Press.

Gulliver, A., Griffiths, K. M., \& Christensen, H. (2010). Perceived barriers and facilitators to mental health help-seeking in young people: a systematic review. $B M C$ Psychiatry, 10(1), 113. doi: 10.1186/1471-244X-10-113

Hart, L. M., Morgan, A. J., Rossetto, A., Kelly, C. M., Mackinnon, A., \& Jorm, A. F. (2018). Helping adolescents to better support their peers with a mental health problem: A cluster-randomised crossover trial of teen Mental Health First Aid. Australian and New Zealand Journal of Psychiatry, 52(7), 638-651. 
ADOLESCENT HELP-SEEKING

Hayes, A. (2013). Introduction to Mediation, Moderation, and Conditional Process

Analysis: A Regression-Based Approach. New York, NY: The Guilford Press. doi:

10.1111/jedm.12050

Jorm, A. F., Korten, A. E., Jacomb, P. A., Christensen, H., Rodgers, B., \& Pollitt, P. (1997). "Mental health literacy": A survey of the public's ability to recognise mental disorders and their beliefs about the effectiveness of treatment. Medical Journal of Australia, 166(4), 182.

Kõlves, K., Milner, A., McKay, K., \& de Leo, D. (2012). Suicide in Rural and Remote Areas of Australia. Brisbane, Australia: Australian Institute for Suicide Research and Prevention.

Lam, L. T. (2014). Mental health literacy and mental health status in adolescents: A population-based survey. Child and Adolescent Psychiatry and Mental Health, 8(26). doi: 10.1186/1753-2000-8-26

Lawrence, D., Johnson, S., Hafekost, J., Boterhoven de Haan, K., Sawyer, M., Ainley, J., \& Zubrick, S. R. (2015). The Mental Health of Children and Adolescents. Report on the Second Australian Child and Adolescent Survey of Mental Health and Wellbeing. 
ADOLESCENT HELP-SEEKING

Littlefield, L. (2008). Towards a comprehensive national early intervention program for

children with mental health problems. Australian E-Journal for the Advancement of

Mental Health, 71), 10-14. doi: 10.5172/jamh.7.1.10

Lubman, D. I., Berridge, B. J., Blee, F., Jorm, A. F., Wilson, C. J., Allen, N. B., McKay-

Brown, L., Proimos, J., Cheetham, A., \& Wolfe, R. (2016). A school-based health

promotion programme to increase help-seeking for substance use and mental

health problems: study protocol for a randomised controlled trial. Trials, 17, 393.

https://doi.org/10.1186/s13063-016-1510-2

McGorry, P. D., \& Mei, C. (2018). Early intervention in youth mental health: progress

and future directions. Evidence Based Mental Health, 21(4), 182-184. doi:

10.1136/ebmental-2018-300060

McGorry, P., \& Purcell, R. (2009). Youth mental health reform and early intervention:

Encouraging early signs. Early Intervention in Psychiatry, 3(3), 161-162. doi:

10.1111/j.1751-7893.2009.00128.x

Mission Australia \& Black Dog Institute. (2017). Youth mental health report: Youth

Survey 2012 -16. Sydney, Australia: Mission Australia

Mission Australia. (2018a). Youth survey 2018. Retrieved from 


\section{ADOLESCENT HELP-SEEKING}

https://www.missionaustralia.com.au/publications/youth-survey/824-mission-

australia-youth-survey-infographic-2018

Mission Australia. (2018b). Youth survey report 2018. From city to country: comparing

major cities and regional areas. Retrieved from

https://www.missionaustralia.com.au/publications/research/young-people/826-from-

city-to-country-comparing-major-cities-and-regional-areas-youth-survey-report2018/file

Murray, C. (2005). Young People's Help-Seeking: An alternative model. SAGE Publications, 12(4), 479-494. doi: 10.1177/0907568205058607

O'Connell, M. E., Boat, T., \& Warner K E. (2009). Preventing mental, emotional, and behavioral disorders among young people: Progress and possibilities. Preventing Mental, Emotional, and Behavioral Disorders Among Young People. doi:

$10.17226 / 12480$

O'Connor, M., \& Casey, L. (2015). The Mental Health Literacy Scale (MHLS): A new scale-based measure of mental health literacy. Psychiatry Research, 229(1-2), 511-516. doi: 10.1016/j.psychres.2015.05.064

Ratnayake, P., \& Hyde, C. (2019). Mental Health Literacy, Help-Seeking Behaviour and 


\section{ADOLESCENT HELP-SEEKING}

Wellbeing in Young People: Implications for Practice. Educational and

Developmental Psychologist, 36(1), 16-21. doi: 10.1017/edp.2019.1

ReachOut Australia, \& Mission Australia. (2018). Lifting the weight. Understanding

young people's mental health and service needs in regional and remote Australia.

Retrieved from

https://www.google.com/url?sa=t\&rct=j\&q=\&esrc=s\&source=web\&cd=1\&ved=2ahU

KEwiMr6jwuOzfAhXM7IMKHRHiDi8QFjAAegQIAhAB\&url=https\%3A\%2F\%2Faifs.g

ov.au\%2Fcfca\%2F2018\%2F07\%2F09\%2Freport-lifting-weight-understanding-

young-peoples-mental-health-and-service-needs\&usg

Reavley, N. J., \& Jorm, A. F. (2012). Stigmatising attitudes towards people with mental disorders: Changes in Australia over 8years. Psychiatry Research, 197(3), 302206. doi: 10.1016/j.psychres.2012.01.011

Rickwood, D., Cavanagh, S., Curtis, L., \& Sakrouge, R. (2004). Educating Young People about Mental Health and Mental Illness: Evaluating a School - Based Programme. International Journal of Mental Health Promotion, 6(4), 23-32. doi: $10.1080 / 14623730.2004 .9721941$

Rickwood, D., Deane, F. P., \& Wilson, C. J. (2007). When and how do young people 


\section{ADOLESCENT HELP-SEEKING}

seek professional help, 187(7), 35-39.

Rickwood, D., Deane, F. P., Wilson, C. J., \& Ciarrochi, J. V. (2005). Young people's help-seeking for mental health problems. Australian E-Journal for the Advancement of Mental Health, 4(3), 1-34. doi: 10.5172/jamh.4.3.218

Rickwood, D. J. (1995). The effectiveness of seeking help for coping with personal problems in late adolescence. Journal of Youth and Adolescence, 24(6), 685-703. doi: 10.1007/BF01536951

Rickwood, D. J., \& Braithwaite, V. A. (1994). Social-psychological factors affecting helpseeking for emotional problems. Social Science \& Medicine, 39(4), 563-572.

Rickwood, D. J., \& Thomas, K. (2012). Conceptual measurement framework for helpseeking for mental health problems. Psychology Research and Behavior Management, 5, 173-183. doi: 10.2147/PRBM.S38707

Rickwood, D. J., Thomas, K., \& Bradford, S. (2012). Help-seeking measures in mental health: A rapid review. Retrieved from https://www.saxinstitute.org.au/wpcontent/uploads/02_Help-seeking-measures-in-mental-health.pdf

Riebschleger, J., Grove, C. J., Cavanaugh, D., \& Costello, S. C. (2017). Mental health literacy content for children of parents with a mental illness: Thematic analysis of a literature 


\section{ADOLESCENT HELP-SEEKING}

review. Brain Sciences, 7(11), 1-19. [141]. https://doi.org/10.3390/brainsci7110141

Rughani, J., Deane, F. P., \& Wilson, C. J. (2011). Rural adolescents' help-seeking

intentions for emotional problems: The influence of perceived benefits and stoicism.

Australian Journal of Rural Health, 19(2), 15-20. doi: 10.1111/j.1440-

1584.2011.01185.x

Sawyer, M., Arney, F. M., Baghurst, P. A., Clark, J. J., Graetz, B. W., Kosky, R. J.,

Nurcombe, B., Patton, G. C., Prior, M. R., Raphael, B., Rey, J. M., Whaites, L. ., \& Zubrick, S. . (2001). The Mental Health of Young People in Australia: Key Findings from the Child and Adolescent Component of the National Survey of Mental Health and Well-Being. Australian \& New Zealand Journal of Psychiatry, 35(6), 806-814. https://doi.org/10.1046/j.1440-1614.2001.00964.x

Vogel, D. L., \& Wester, S. R. (2003). To seek help or not to seek help: The risks of selfdisclosure. Journal of Counseling Psychology, 50(3), 351-361. doi: 10.1037/00220167.50.3.351

Vogel, D. L., Wester, S. R., Wei, M., \& Boysen, G. A. (2005). The role of outcome expectations and attitudes on decisions to seek professional help. Journal of Counseling Psychology, 52(4), 459-470. doi: 10.1037/0022-0167.52.4.459 


\section{ADOLESCENT HELP-SEEKING}

Wilson, C. J., Deane, F. P., Ciarrochi, J. V, \& Rickwood, D. (2005). Measuring help

seeking intentions: Properties of the General Help Seeking Questionnaire.

Canadian Journal of Counselling, 39(1), 15-28.

World Health Organization. (2018). Mental health: strengthening our response.

Retrieved April 1, 2019, from https://www.who.int/news-room/fact-

sheets/detail/mental-health-strengthening-our-response 


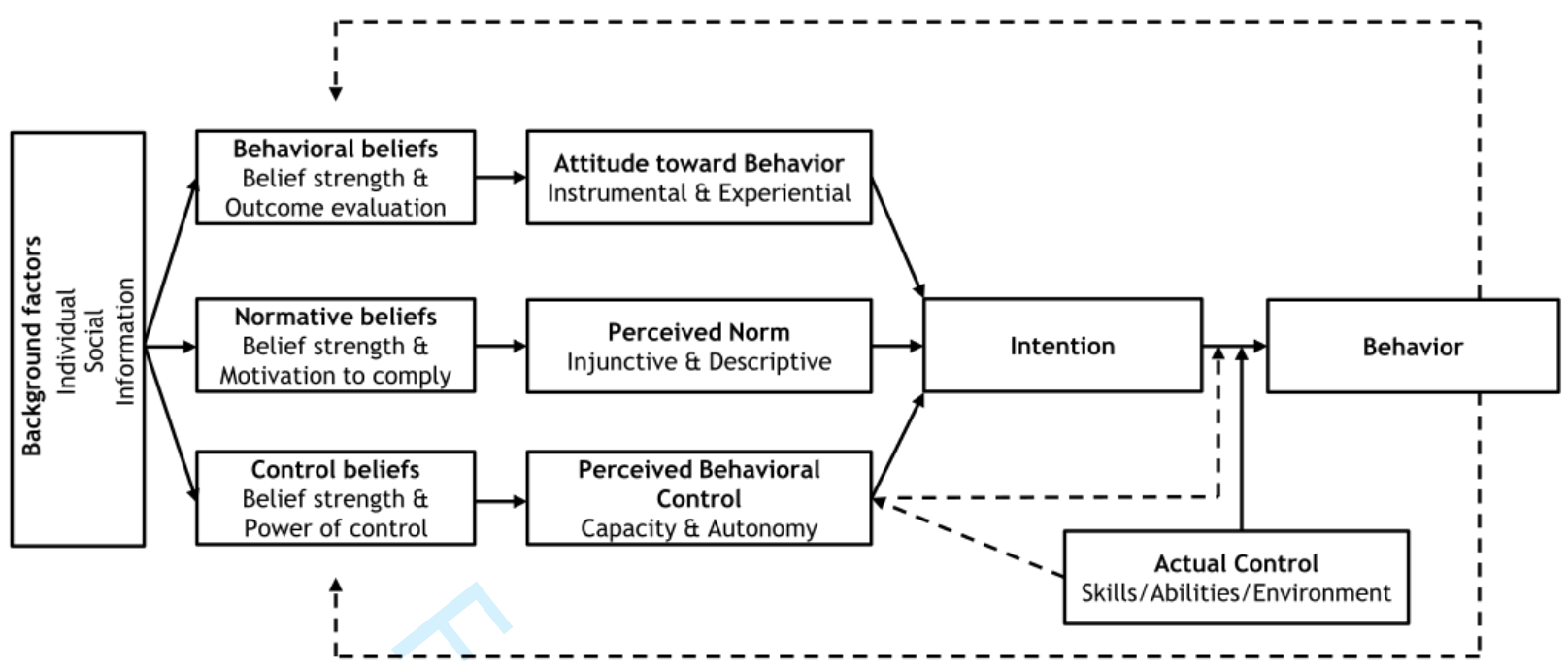

Figure 1. Reasoned Action Approach (Fishbein \& Ajzen, 2010, pg 22) 


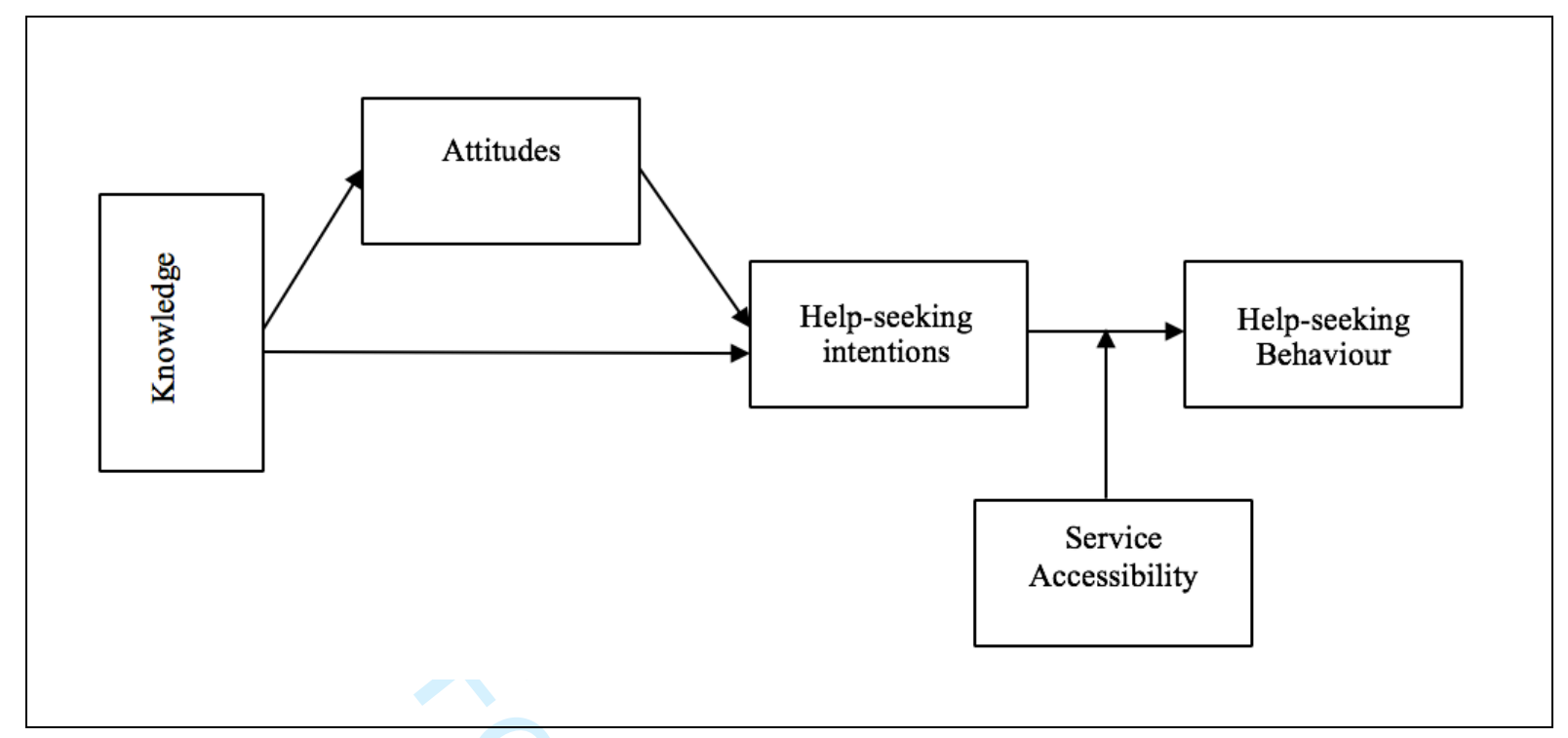

Figure 2. Application of the Reasoned Action Approach (adapted from Fishbein \& Ajzen, 2010) to Help-Seeking for Mental Health Concerns 


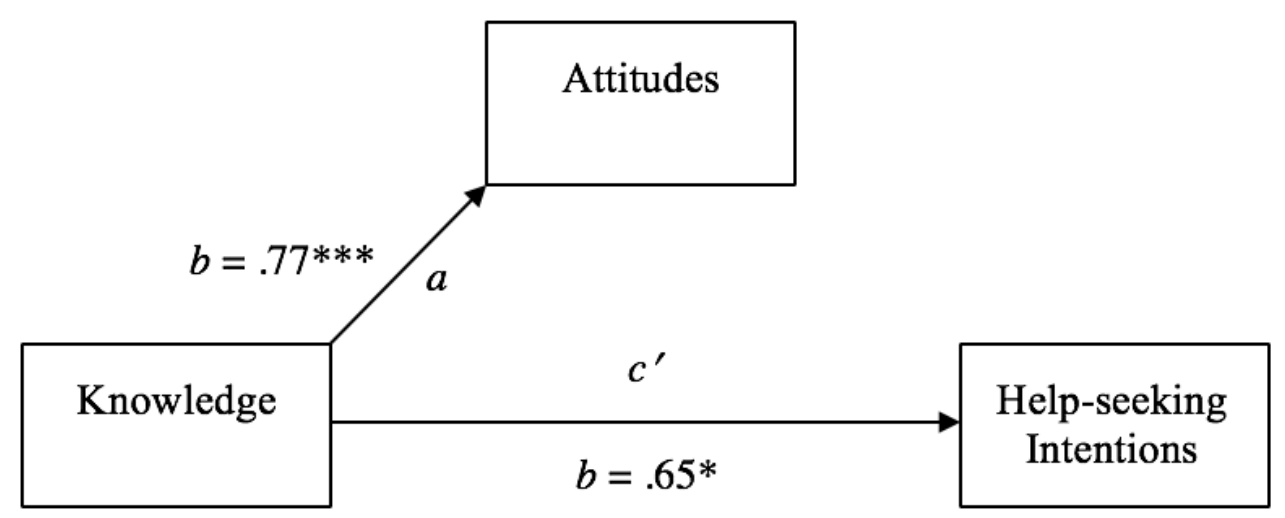

Figure 3. Path Analysis- Knowledge, Attitudes and Help-Seeking Intentions 


\section{University Library}

\section{- M M N E R VA A gateway to Melbourne's research publications}

Minerva Access is the Institutional Repository of The University of Melbourne

Author/s:

Pearson, S; Hyde, C

Title:

Influences on adolescent help-seeking for mental health problems

Date:

2021-06-01

Citation:

Pearson, S. \& Hyde, C. (2021). Influences on adolescent help-seeking for mental health problems. JOURNAL OF PSYCHOLOGISTS AND COUNSELLORS IN SCHOOLS, 31 (1), pp.110-121. https://doi.org/10.1017/jgc.2020.28.

Persistent Link:

http://hdl.handle.net/11343/258902 